NBER WORKING PAPER SERIES

\title{
PREFERENCES AND HETEROGENEOUS TREATMENT EFFECTS IN A PUBLIC SCHOOL CHOICE LOTTERY
}

\author{
Justine S. Hastings \\ Thomas J. Kane \\ Douglas O. Staiger \\ Working Paper 12145 \\ http://www.nber.org/papers/w12145 \\ NATIONAL BUREAU OF ECONOMIC RESEARCH \\ 1050 Massachusetts Avenue \\ Cambridge, MA 02138 \\ April 2006
}

The authors thank the Charlotte-Mecklenburg School district for making this project possible. Sean Hundtofte and Orkun Sahmali provided outstanding research assistance. We would also like to thank Joseph Altonji, Patrick Bayer, Steven Berry, David Card, Kenneth Chay, Philip Haile, Fabian Lange, James Powell and participants at various seminars for helpful comments and discussion. The project is funded by grants from the Institution for Social and Policy Studies at Yale University and the US Department of Education. The views expressed herein are those of the author(s) and do not necessarily reflect the views of the National Bureau of Economic Research.

(C) 2006 by Justine S. Hastings, Thomas J. Kane, and Douglas O. Staiger. All rights reserved. Short sections of text, not to exceed two paragraphs, may be quoted without explicit permission provided that full credit, including $(\mathcal{O}$ notice, is given to the source. 
Preferences and Heterogeneous Treatment Effects in a Public School Choice Lottery Justine S. Hastings, Thomas J. Kane, and Douglas O. Staiger

NBER Working Paper No. 12145

April 2006, Revised July2007

JEL No. I0,I2,I20,I28

\begin{abstract}
$\underline{\text { ABSTRACT }}$
This paper combines a model of parental school choice with randomized school lotteries in order to understand the effects of being assigned to a first-choice school on academic outcomes. We outline a simple framework in which those who place the highest weight on academics when choosing a school benefit the most academically when admitted. Although the average student does not improve academically when winning a school lottery, this average impact conceals a range of impacts for identifiable subgroups of students. Children of parents whose choices revealed a strong preference for academic quality experienced significant gains in test scores as a result of attending their chosen school, while children whose parents weighted academic characteristics less heavily experienced academic losses. This differential effect is largest for children of parents who forfeit the most in terms of utility gains from proximity and racial match to choose a school with stronger academics. Depending on one's own race and neighborhood, a preference for academic quality can either conflict with or be reinforced by other objectives, such as a desire for proximity and same-race peers.
\end{abstract}

Justine S. Hastings

Yale University

P.O. Box 208264

New Haven, CT 06520-8264

and NBER

justine.hastings@yale.edu

Thomas J. Kane

Harvard Graduate School of Education

Gutman Library, Room 455

Appian Way

Cambridge, MA 02138

and NBER

kaneto@gse.harvard.edu
Douglas O. Staiger

Dartmouth College

Department of Economics

HB6106, 301 Rockefeller Hall

Hanover, NH 03755-3514

and NBER

douglas.staiger@dartmouth.edu 


\section{Introduction}

Public school choice plans are intended to improve academic achievement, by allowing parents to choose a school other than their neighborhood school and by giving local schools an incentive to attract and retain students. Many urban public school districts are experimenting with some form of school choice. In fact, the federal No Child Left Behind Act (NCLB) requires that school districts give students at persistently underperforming public schools the option to choose a higher-achieving public school. Nevertheless, there is little empirical evidence that offering disadvantaged students more choices will lead to any substantial increase in academic achievement.

A number of papers have used random assignment to estimate the effect on academic outcomes of attending a school other than the local public school. Most of these papers identify the average treatment effect using lottery assignment to over-subscribed public schools or the randomization of private school vouchers (Witte et al. (1995), Greene et al. (1997), Rouse (1998), Peterson et al. (1998), Mayer et al. (2002), Krueger and Zhu (2004), Cullen et al. (2006), Hastings et al. (2006b)). ${ }^{1}$ Taken together, these papers fail to find robust impacts on average academic outcomes.

However, as noted in many of these papers, parents may have a variety of reasons for choosing schools, and we might expect this to lead to heterogeneous impacts of attending a first choice school on academic achievement (Heckman et al. (1997), Heckman (1997), Heckman, et al. (2006)). The child of an academically oriented parent who chooses to send her child across town to attend a high-performing school may experience larger gains from school choice than the child of a parent who chooses a school primarily for convenience - particularly when the most convenient school is low performing. Thus, the average effect of attending a first choice school may be zero even if schools do have offsetting positive and negative impacts for subsets of children.

\footnotetext{
${ }^{1}$ An earlier non-experimental literature compared academic outcomes of those students who chose to attend private, charter or magnet schools to those students who remained in their neighborhood school (Coleman et al. (1982), Bryk et al. (1993), Blank (1983), Gamoran (1996), Evans and Schwab (1995), Neal (1997), Altonji et al. (2002)).
} 
In this paper we use the choice rankings of parents following the introduction of district-wide school choice in the Charlotte-Mecklenburg School District (CMS) along with lottery assignment of students to first choice schools to shed light on the factors that drive parental choice and their relationship to subsequent student outcomes. In 2002, CMS introduced a district-wide choice plan to end three decades of busing for integration. All parents in the district were asked to provide their top three school choices and a lottery was used to determine admission to oversubscribed schools. We show that parents' choices were very heterogeneous, and outline a simple model that illustrates how the academic gains from attending a first-choice school should be positive for parents who place a high implicit weight on academics when choosing a school, and potentially negative for parents who place low weights on academics and high weights on other factors that are negatively correlated with academics (e.g. geographic proximity or fraction minority). We then use the rich choice data and lottery assignment to test this model in the data, explicitly allowing for heterogeneity in treatment effects generated by the underlying preferences that drove parents' school choices.

In order to estimate the implicit weight each parent placed on academics when choosing a school, we first estimate the distribution of preferences for school characteristics using a mixed logit model (McFadden and Train (2000),Train (2003)). ${ }^{2}$ This random utility model allows parents to have heterogeneous preferences for school characteristics that depend on observable demographics as well as idiosyncratic factors. The estimates from this model can be used to calculate a posterior estimate of the implicit weight that each parent placed on academics when choosing a school. ${ }^{3}$ This implicit weight is effectively a non-linear index of baseline characteristics, combining all of the information about the student, their proximity to each school, the characteristics of each school and the schools their parents selected into a single summary statistic. It measures how unexpected a parent's choices were relative to what a typical parent would have chosen given their demographics and geographic location. For example, if a parent chooses schools with high test scores in each of their three choices, passing over closer

\footnotetext{
${ }^{2}$ For a more complete discussion of the effect of school characteristics in determining parental demand, see Hastings et al. (2006a).

${ }^{3}$ Because of the availability in our data of multiple ranked choices for each parent, we are able to identify idiosyncratic heterogeneity in preferences based on systematic differences in the sequential choices made by parents of similar students facing similar school options (Berry et al. (2004)).
} 
schools that most other parents would have preferred, we would infer that they place a high implicit weight on academics.

We then turn to the lottery assignments to investigate if students experience academic gains from attending a first-choice school. Consistent with the prior literature, we find no average gain in test scores from attending a first choice school. We do, however, find significant positive gains among white students and students of higherincome families, and negative but insignificant impacts for African Americans and children of lower-income families. We show that this pattern of subgroup differences in gains is consistent with differences in underlying preferences and the trade-offs parents face. We do this in two ways. First, we show that the average weight placed on academics is positively correlated with the average treatment effect across subgroups (although the differences in subgroup impacts are too imprecisely estimated to be statistically distinguishable). Second we allow the treatment effect of attending a first choice school to vary explicitly with the implicit weight that parents place on academics. We find that the treatment effect varies significantly and positively with this weight. Students with estimated weights on school test scores at the $95^{\text {th }}$ percentile experienced significant rises in End of Grade test scores of approximately 0.1 standard deviations. These students are most likely to be white and have higher income levels, thus generating the significant subgroup impacts by race and income. In contrast, students placing little value on academics actually experienced declines in academic achievement. We show that this is strongest for African Americans, who must trade-off academic gains against utility gains from attending a school with a high proportion of minority students.

This paper offers a model and an approach that explains and gives an economic interpretation to heterogeneous treatment effects across subgroups of students. Prior research has speculated that differing preferences may contribute to the observed differences in impacts across subgroups, but has not had a setting in which to both estimate the underlying determinants of school choice and the resulting outcomes from attending a first choice school. Our results suggest that differing impacts across subgroups can be largely explained by underlying differences in parents' willingness to trade off expected gains in academic achievement for gains in utility along other dimensions, such as proximity or school racial composition. More generally, this implies 
that the impact of school choice on academic outcomes will depend on both the willingness of parents to make these tradeoffs, and the extent to which the available school choices require such tradeoffs to be made.

This paper proceeds in five main sections. The first section lays the background for the data and estimation by describing key details of the CMS school choice plan. The second section outlines the relationship between expected academic outcomes and preferences in a school choice plan, where parents choose schools based on expected academic achievement and other school characteristics, and students are then granted admission to schools by lottery. In the third section, we generate estimates of the preferences for academic achievement. We incorporate these preference estimates into our final estimation of the effect of attending a first choice school on academic outcomes. The final section concludes.

\section{Background: The CMS School Choice Plan}

Before the introduction of a school choice plan in the fall of 2002, the CharlotteMecklenburg public school district (CMS) operated under a racial desegregation order for three decades. In September 2001, the U.S. Fourth Circuit Court of Appeals declared the school district "unitary" and ordered the district to dismantle the race-based student assignment plan by the beginning of the next school year. In December of 2001, the school board voted to approve a new district-wide public school choice plan.

In the spring of 2002, parents were asked to submit their top three choices of school programs for each child. Each student was assigned a "home school" in their neighborhood, often the closest school to them, and was guaranteed a seat at this school. Magnet students were similarly guaranteed admission to continue in their current magnet programs. Admission for all other students was limited by grade-specific capacity limits set by the district. Students could choose any school in the district. However, transportation was only guaranteed to schools in a student's quadrant of the district (the district was split into 4 quadrants called 'choice zones'). The district allowed significant increases in enrollment in many schools in the first year of the school choice program in an expressed effort to give each child one of their top three choices. In the spring of 2002, 
the district received choice applications for approximately 105,000 of 110,000 students. Admission to over-subscribed schools was determined by a lottery system as described below.

Once the district was declared "unitary" and the court order requiring race-based busing was terminated, they could no longer draw boundaries based on the racial composition of a neighborhood. As a result, the former school assignment zones, which often paired non-contiguous black and white neighborhoods, were dramatically redrawn. Under the choice plan, 43 percent of parcels were assigned to a different elementary grade 'home school' than they were assigned to the year before under the busing system. At the middle school and high school levels this number was 52 and 35 percent respectively. Therefore, the 2002-2003 home school for many students is often not the school they would have been assigned at the time they chose their residence. This dramatic change in school assignment zones, the simultaneous introduction of a sweeping school choice plan, and the assignment of students to high-demand schools by lottery provides a unique opportunity to estimate parental preferences for schools and model the heterogeneous impact of attending a chosen school on academic outcomes.

\section{Lottery Assignments}

Approximately one third of the schools in the district were oversubscribed. The district implemented a lottery system for determining enrollments in those oversubscribed schools. Under the lottery system, students choosing non-home schools were first assigned to priority groups and student admission was then determined by a lottery number. The priority groups for district schools were arranged in lexicographic order based on the following priorities:

Priority 1: Student who had attended the school in the prior year. (Students were subdivided into 3 priority groups depending upon their grade level, with students in terminal grades-grades 5,8 and 12-given highest priority.)

Priority 2: Free-lunch eligible student applying to school where less than half the students were free-lunch eligible.

Priority 3: $\quad$ Student applying to a school within their choice zone. 
Students listing a given school as their first choice were sorted by priority group and a randomly assigned lottery number. ${ }^{4}$ Any slots remaining after home school students were accommodated were assigned in order of priority group and random number. ${ }^{5}$ If a school was not filled by those who had listed it as a first choice, the lottery would repeat the process with those listing the school as a second choice, using the same priority groups as above. However, for many oversubscribed schools, the available spaces were filled up by the time the second choice priority groups came up.

Students who were not assigned one of their top choices were placed on a waiting list. About $19 \%$ of students winning the lottery to attend their first choice schools subsequently attended a different school, with $13 \%$ choosing to attend their home school instead and another $6 \%$ choosing to attend a different school entirely, with most of these students changing address. When slots became available, students were taken off the wait list based on their lottery number alone, without regard for their priority group.

\section{Potential for Strategic Choice}

The lottery mechanism used by the Charlotte-Mecklenburg schools was a 'firstchoice-maximizer,' in which slots were first assigned to all those listing a given school as a first choice before moving to those listing the school as a second or third choice. In such a mechanism, parents with poor home school options may have an incentive to misstate their preferences - not listing their most preferred school if it had a low probability of admission (Glazerman and Meyer (1994), Abdulkadiroglu and Sonmez (2003), Abdulkadiroglu et. al (2006)). Instead, they may have hedged their bets by listing a less preferred option with a higher probability of admission in order to avoid being assigned to their home school. Such strategic behavior would imply that student choices would not reflect true preference orderings for schools - to the extent that students are not listing their preferred match due to strategic hedging on quality.

\footnotetext{
${ }^{4}$ The random number was assigned by a computer using an algorithm that we verified with CMS computer programmers.

5 Once any sibling was admitted to a school, other siblings could choose to attend the school. We dropped those who were admitted to a school because of a sibling preference.
} 
However, there were a number of reasons why such strategic behavior was probably rare in the first year of the choice plan that we are studying. First, parents did not know the details of how the lottery system would be operated. The handful of district officials who knew the lottery details were not allowed to communicate them to parents. Parents were never given their actual lottery numbers. The district also told parents that they would make every attempt to give each student admission to one of their chosen schools, and instructed them to list what they wanted. In order to accommodate demand, the district substantially expanded capacity at popular schools. In addition, the district gave a 'priority boost' to low-income students choosing to attend schools with low concentrations of low income students. Hence, choices for top schools by students with under-performing home schools would be given top priority. This would counteract the incentive for these students to hedge their choices as outlined above.

If there were widespread strategic behavior by parents, we would expect those with low-quality default schools to hedge their bets and list less desirable schools for which they might have a higher probability of admission. In another paper, Hastings et al. (2006a), we test whether parents with exogenous changes in the quality of their default school produced by the redistricting had lower preferences for high-quality schools as would be predicted if parents were behaving strategically. Perhaps because of the uncertainty about the mechanism and the newness of the system, we did not find evidence that strategic behavior played a significant role in this first year of school choice. $^{6}$

\section{Preferences, Choices and Expected Treatment Effects}

We have access to administrative data for all students in CMS for the year before and after the implementation of school choice. Throughout the analysis, we focus on students entering grades 4 through 8 since we have baseline test scores for this group of students for North Carolina End of Grade Tests. For each student, we have the choice forms submitted to CMS, allowing a parent to specify up to three choices for their child's school. In addition to the student choices, our data contain student characteristics for the

\footnotetext{
${ }^{6}$ For the details of this test, as well as for further specification checks on the mixed logit demand estimation, please see Hastings et al. (2006a), Section VIII, pp. 21-27.
} 
years before and after school choice, including geo-coded residential location, race, gender, lunch-subsidy recipient status, and student test scores for standardized North Carolina End of Grade exams in math and reading, and school assignment. The data also include student-level lottery numbers, lottery outcomes and school assignments for the 2002-2003 school choice lottery.

It is clear that parents have very heterogeneous preferences over school characteristics. As reported in Figure 1, approximately $20 \%$ of students chose schools that had lower test scores than the school they had guaranteed admission to. In addition, among those with the same elementary home school for 2002-03, parents on average listed 10 different elementary schools as their first choice. ${ }^{7}$ The range of choices made suggests that heterogeneous preferences may play a key role in school selection, and may therefore generate differential gains in academic achievement.

A simple model illustrates how the expected gains in academic achievement will depend on parental preferences. Suppose that parents choose schools for both the expected academic gain for their child, but also for other reasons, such as proximity or racial composition. Consider the following utility function of parent $i$ for school $j$

$$
U_{i j}=\beta_{i}^{A} A_{i j}+V_{i j}
$$

where $A_{i j}$ is the expected academic achievement of student $i$ if she attends school $j, V_{i j}$ is the utility for student $i$ from attending school $\mathrm{j}$ along non-academic dimensions, and $\beta_{i}^{A}$ is the weight that parent $i$ places on academic achievement relative to non-academic dimensions. The utility gain from attending the first choice over the alternative school is:

$$
\Delta U=\beta_{i}^{A} \Delta A+\Delta V
$$

where delta denotes the difference in variables between school alternatives $k$ and $j$. A student will choose an alternative school over their home school only if the utility gain is positive, i.e. $\Delta U>0$. Among students choosing an alternative school over their home

\footnotetext{
${ }^{7}$ This statistic excludes heterogeneity in choices generated solely by heterogeneity in prior-year school assignment under the bussing system. If we include choices driven by preferences for prior-year schools by students with different prior-year schools under bussing, but the same new home-school assignment area under choice, this statistic increases to 14.6 .
} 
school, the expected academic gain of a student randomized into their $1^{\text {st }}$ choice school is given by: ${ }^{8}$

$$
E\left(\Delta A \mid \beta_{i}^{A} \Delta A+\Delta V>0\right)
$$

In this simple framework, students with high $\beta_{i}^{A}$ have a positive expected treatment effect (gain in academic achievement from attending the first-choice school). In fact, as $\beta_{i}^{A}$ gets very large, the expected treatment effect alone determines choice and, therefore, must be positive for all students who choose an alternative school. For a student with low $\beta_{i}^{A}$ (near zero), the expected treatment effect is ambiguous. If $\Delta A$ and $\Delta V$ are independent and $\Delta A$ is mean zero, then the expected treatment effect is zero, i.e. $E(\Delta A \mid \Delta V>0)=0$. If $\Delta A$ is negatively correlated with $\Delta V$ - as may be the case for some non-academic dimensions such as proximity and percent African American - then the treatment effect will be negative for students, unless their parents' preference for academic quality is sufficiently strong to overcome the negative trade-off. That is, the parent of a student in a neighborhood served by a low-performing school or the parent of a minority student who wants her child to attend a school with same-race peers may give up gains in her child's academic achievement if her preference for academics is not large enough to counter-balance her preferences for non-academic factors. Hence, this basic framework generates the prediction that the expected treatment effect is positive for all students with a strong preference for academic achievement. Among students with weaker preferences for academic achievement, the expected treatment effect will depend on the tradeoffs that parents face. The treatment effect could even be negative if expected academic achievement is sufficiently negatively correlated with other valued school characteristics.

\section{Estimating Preferences Using a Random Utility Model}

Accordingly, we use parents' school choices to infer preferences for academic achievement and then use them to test if differences in underlying preferences and the trade-offs parents face affect the impact that attending a first choice school has on a

\footnotetext{
${ }^{8}$ As noted earlier, the lottery was run as a 'first-choice maximizer'. Because of this, most students who did not win the lottery for their parents' first choice school were assigned to their home school.
} 
student's academic achievement. Let $\mathrm{U}_{\mathrm{ij}}$ be the expected utility of individual $i$ from attending school $j$. Suppose that utility is a linear function of the academic achievement of student $i$ at school $j, A_{i j}$, and other school-student characteristics, $Z_{i j}$, such as distance from home, busing availability, and racial composition. Thus, expected utility is given by:

$$
U_{i j}=\beta_{i}^{A} A_{i j}+\gamma_{i} Z_{i j}+\omega_{i j}
$$

where $\beta_{i}^{A}$ and $\gamma_{i}$ represent preference parameters for person $\mathrm{i}$, and $\omega_{i j}$ represents an unobserved idiosyncratic preference of student $i$ for school $j$.

Furthermore, suppose that the expected academic achievement for student $\mathrm{i}$ attending school $\mathrm{j}$ depends on the average test score at school $j$ ( $S_{j}$ with a coefficient normalized to one), other observable characteristics of the school $\left(Z_{i j}\right)$, plus a mean zero deviation that is known to the parent $\left(v_{i j}\right)$.

$$
A_{i j}=S_{j}+\alpha Z_{i j}+v_{i j}
$$

In this model, parents base their expectations of academic achievement on observable school characteristics plus idiosyncratic factors affecting their child. ${ }^{9}$ This specification allows for the possibility that non-academic factors such as proximity may affect academic achievement (for example, through longer bus rides) and also allows for the possibility that parents adjust school test scores for racial composition of the school (the "value-added" approach). This adjustment can be different for parents with different observables (such as race) if preferences for school characteristics are allowed to vary with student observable characteristics.

Using equation (5), we can re-write the indirect utility function as:

$$
U_{i j}=\beta_{i}^{A} S_{j}+\beta_{i}^{Z} Z_{i j}+\varepsilon_{i j}=X_{i j} \beta_{i}+\varepsilon_{i j}
$$

\footnotetext{
${ }^{9}$ An alternative specification would further multiply the right hand side of (5) by an individual-specific coefficient, representing an individual-specific return to attending a more academically oriented school. This alternative specification results in an identical empirical specification of indirect utility in (6), but with a different interpretation - a higher coefficient on school test score could represent either a stronger preference for academics or a higher return to academic achievement from attending an academically oriented school.
} 
where $\varepsilon_{i j}=\beta_{i}^{A} v_{i j}+\omega_{i j}, \beta_{i}^{Z}=\gamma_{i}+\beta_{i}^{A} \alpha, X_{i j}=\left[S_{j}, Z_{i j}\right]$, and $\beta_{i}=\left[\beta_{i}^{A}, \beta_{i}^{Z}\right]$. Assuming that the $\varepsilon_{i j}$ are independently distributed extreme value, we get the typical logit functional form for the probability of choosing school $j .{ }^{10}$ With distributional assumptions on the preference parameters, we have a mixed logit utility model. The mixed logit can approximate any random utility model, given appropriate mixing distributions and explanatory variables (Dagsvik (1994), McFadden and Train (2000)).

Even though the expected academic achievement for student $i$ attending school $j$ $\left(A_{i j}\right)$ is not observed directly, the weight placed on academic achievement can be estimated. The weight on academic achievement $\left(\beta_{i}^{A}\right)$ is identified in the mixed logit model because school test scores are assumed to influence utility only through their effect on academic achievement, whereas other school characteristics in $Z_{i j}$ may affect utility directly as well as indirectly through expected academic achievement. Obtaining direct estimates of $A_{i j}$ would require additional structural assumptions to identify how academic achievement depends on observable school characteristics and idiosyncratic factors affecting a child's academic performance at each school $\left(\alpha Z_{i j}+v_{i j}\right) .{ }^{11}$ Rather than impose additional assumptions, our analysis focuses on the more fundamental implication that parents placing a high weight on school test scores (high- $\beta_{i}^{A}$ ) should be more likely to choose schools that increase their child's academic achievement. While parents may prefer schools with high test scores for non-academic reasons as well (e.g., status or social connections), it is reasonable to assume academics are their primary concern. An important benefit of this approach is that we do not have to completely specify how school and student characteristics combine to produce academic

\footnotetext{
${ }^{10}$ Note that estimation involves normalizing the variance of $\varepsilon_{i j}$. Since $\operatorname{Var}\left(\varepsilon_{i j}\right)$ is an increasing function of $\beta_{i}{ }^{A}$, normalization will reduce the estimate of $\beta_{i}{ }^{A}$ for high- $\beta_{i}{ }^{A}$ types. While this will act to understate the estimated variation in $\beta_{i}^{A}$ in the final model, it does not affect the relative rankings of individuals with respect to $\beta_{i}^{A}$ - which is the information we use to estimate heterogeneous treatment effects.

${ }^{11}$ For example, if $A_{i j}=X_{j} \beta_{i}+v_{i j}$ and $V_{i j}=Z_{i j} \gamma_{i}+\omega_{i j}$, with $v_{i j}$ i.i.d. normal and $\omega_{i j}$ i.i.d. extreme value, and no common variables in $\mathrm{X}$ and $\mathrm{Z}$, then one can estimate $\mathrm{E}(\Delta \mathrm{A} \mid \Delta \mathrm{U}>0)$ directly from the random utility model. We estimated models of this form and found that they performed poorly in terms of predicting the magnitude of the treatment effect, suggesting that either our assumptions were too restrictive or the necessary student-choice level idiosyncratic parameters were poorly identified.
} 
achievement: we just need to know that academic achievement was important to the parent in choosing a school.

We estimate the underlying preference parameters in this random utility model using simulated maximum likelihood techniques (Train (2003)). The probability that individual $i$ chooses schools $\left(j^{1} j^{2}, j^{3}\right)$ is given by:

$$
\begin{aligned}
& P_{i}\left(j^{1}, j^{2}, j^{3}\right)=\operatorname{Pr}\left\{\left(U_{i j^{1}}>U_{i k} \forall k \in J_{i}^{1}\right) \cap\left(U_{i j^{2}}>U_{i k} \forall k \in J_{i}^{2}\right) \cap\left(U_{i j^{3}}>U_{i k} \forall k \in J_{i}^{3}\right)\right\} \\
& =\int \prod_{c=1}^{3} \frac{e^{X_{i j^{c}} \beta}}{\sum_{k \in J_{i}^{c}} e^{X_{i k} \beta}} f(\beta \mid \mu, \theta) d \beta
\end{aligned}
$$

We assume that $\beta \sim f(\beta \mid \mu, \theta)$, where $f(\cdot)$ is a joint-normal mixing distribution, $\mu$ denotes the mean, and $\theta$ represents the variance parameters. The term inside the integrand represents the probability of observing the three ranked choices conditional on the preference coefficients $(\beta)$ : this is the product of three logit probabilities evaluated at $\beta_{i}$, corresponding to the probability of making each choice from among the remaining options. ${ }^{12}$ This conditional probability is integrated over the distribution of $\beta$ to yield the unconditional probability of observing the ranked choices. Estimation was by the method of maximum simulated likelihood, using 100 draws of $\beta$ from $f(\cdot)$ for each individual in the data set. The results were not sensitive to the number of draws used. We assume that all random parameters are drawn from a normal or log normal distribution, and allow for correlation among some of the main preference parameters as reported in the tables.

The maximum likelihood results yield parameter estimates for the mean and variance of preferences in the population. We then use Bayes' rule to calculate posterior estimates of the weight each student placed on school scores in the following way (Revelt and Train (1998), Train (2003)):

$$
E\left(\beta_{i}^{A} \mid y_{i}, X_{i j}, \mu, \theta\right)=\frac{\int \beta_{i}^{A} P\left(y_{i} \mid X_{i j}, \beta\right) f(\beta \mid \mu, \theta) d \beta}{P\left(y_{i} \mid X_{i j}, \mu, \theta\right)}
$$

Where $y_{\mathrm{i}}$ denotes the choices the student made. This equation is the expected value of student $i$ 's preference for academics given her characteristics, the choices she made, the

\footnotetext{
${ }^{12}$ For students submitting fewer than three choices, the likelihood is modified in an obvious way to reflect only the probability of the submitted choices.
} 
characteristics of the schools given her location, and the estimated distribution of preferences in the population. We calculate this posterior for each student in our randomized lottery admission group using 1000 draws from the estimated preference distributions in from the mixed logit demand estimation. ${ }^{13}$

This posterior weight on average test scores is what we will use to examine if heterogeneous preferences drive choices and expected treatment effect. Notice that it will vary with demographics if we allow mean preferences to vary with observable family characteristics such as race, lunch status, family income, and student baseline score. However, the posterior weight also captures baseline information on how the choice of the parent differed from the choices of observationally similar parents facing the same choice set. Thus the posterior weight incorporates a large amount of information into one summary statistic in a way that would be difficult to capture with simple subgroups based on student demographics or characteristics of the chosen school.

\section{Demand Estimation Results}

We follow Hastings et al. (2006a) and present mixed logit results from that model here. The model includes key observable school characteristics: the distance from student $i$ to school $j$ (measured in miles along roads), an indicator if the student was eligible for busing to the school, and an indicator if the school was designated as the student's neighborhood school, an indicator if the child attended the school in the prior year, the percent black in the school (in Spring 2003) and its square, and a measure of average test scores in the school (the school level average of all students' standardized math and reading scores in spring of 2003). ${ }^{14}$ Table I lists the independent variables in the indirect utility function and describes how they were constructed.

We allow the mean preference for academic achievement (the coefficient on school test scores) to vary linearly with the student's standardized baseline test score (from the spring of the prior year, standardized by grade level across the district) and the

\footnotetext{
${ }^{13}$ See Train (2003) p. 270 for Monte Carlo Simulations of the accuracy of individual-level parameter estimates and the number of observed choice situations.

${ }^{14}$ We use the average test scores at the end of the first year of choice instead of those at the end of the year before school choice was implemented. Hastings et al. (2006a) presents demand estimation results for various measures of school academic achievement. They find for example that value added measures do a poor job of explaining choices, and that the choice data imply that parents are choosing schools based on levels instead of changes in academic achievement.
} 
median household income in the student's neighborhood for the student's race (measured in $\$ 1000$ 's, using their census block group in 2000, and de-meaned with the countywide median of $\$ 51,000)$. Preferences for distance are constrained to be negative with a $\log$ normal distribution. We allow preferences for proximity and academic quality to be correlated. All other preference distributions are assumed to be independently and normally distributed. We estimate the parameters of the preference distribution separately by race and lunch-subsidy status, thus allowing for full interactions with race and lunch status.

As discussed in more detail in Hastings et al. (2006a), several aspects of the CMS school choice data and experiment are helpful for identifying preferences in our demand estimation. First, the large scale redistricting that occurred with the introduction of school choice helps to identify preference parameters separately from residential sorting. Without redistricting and the multiple-choice responses, residential sorting would potentially confound the preferences for proximity with preferences for other desired school attributes. ${ }^{15}$

Second, historic placement of schools for busing in CMS provides wide variation in school characteristics for families in all socio-economic groups, dampening collinearity problems that may be present in other settings. ${ }^{16}$ Third, approximately $95 \%$ of the 110,000 students submitted choices for the choice plan. Thus we have data for nearly the entire student population-whereas most work using school choice data has been dependent on limited and potentially non-representative subgroups of students.

Fourth, the multiple responses create variation in the choice set by effectively removing the prior chosen school from the subsequent choice set. This choice-set variation allows us to estimate the distribution of preferences for school characteristics from observed substitution patterns for each individual - a stronger source of variation for identification than cross-sectional changes in the choice set based on geographic location (Train (2003), Berry, Levinsohn, and Pakes (2004)). Intuitively, when only a

\footnotetext{
${ }^{15}$ In addition, multiple choices listed by those selecting their home school first further separates preferences for school characteristics from residential sorting by simulating the unavailability of the neighborhood school. For a comparison of preference estimates for the redistricted sub-sample versus the full sample, please see Hastings, Kane and Staiger (2006a). They show that preferences are very similar for the redistricted subsample of students relative to the population.

${ }^{16}$ Hastings et al. (2006a) show that average distance to a top-tier school is the same across all socioeconomic groups.
} 
single $\left(1^{\text {st }}\right)$ choice is observed for every individual, it is difficult to be sure whether an unexpected choice was the result of an unusual error term $\left(\varepsilon_{i j}\right)$ or unusual preferences by the individual $\left(\beta_{i}\right)$ for some aspect of the choice. However, when an individual makes multiple choices that share a common attribute (e.g. high test scores) we can infer that the individual has a strong preference for that attribute, because independence of the additive error terms across choices would make observing such an event very unlikely in the absence of a strong preference.

The final estimation sample includes 36,816 students entering grades 4-8. Estimation is limited to these grades because of the lack of test scores (either baseline or school test scores) in other grades. The means and standard deviations of these variables across the 2.4 million school, student, and choice rank interactions available to our sample of students and schools are reported in Table II. Table III presents the results from the mixed logit demand estimation by race and lunch-recipient status. All of the point estimates were precisely estimated and statistically different from zero at less than the 1 percent level. We report the estimates for the means, standard deviations, and correlation coefficients (where appropriate) for the preference distributions. The discussion of results is focused around the parameters most relevant for our final estimation of the effect of attending a first choice school on academic achievement. For a further discussion of the results and their implications for student sorting and competition on quality in public school choice, please see Hastings et al. (2006a).

The first four rows of coefficients in Table III report the preferences for school test scores by race and lunch-recipient status. The first row of coefficients reports the mean preference for school scores for the average student. It is positive for all four demographic groups, implying that school test scores have a positive effect on choosing a school for the average student. For a student with average baseline test scores and average income, the mean preference for school scores is larger for non-white students (1.80) than for white students (1.17) among students not receiving lunch subsidies. These coefficients imply that a 0.1 increase in average test scores at a school (one tenth of a student-level standard deviation) is associated with a $10 \%-20 \%$ increase in the odds of choosing that school for an average student not receiving lunch subsidies. Preference for 
school scores among students receiving lunch subsidies are lower for both whites and nonwhites, but the difference between whites and nonwhites is similar.

We also allow the mean preference for school test scores to vary with the student's baseline test score and their neighborhood income level. ${ }^{17}$ The third and fourth rows of parameter estimates report the coefficient on the interaction of school scores with income and the student's baseline score respectively. ${ }^{18}$ The coefficients on the income interaction imply that mean preferences for a school's test score (conditional on its racial composition) are increasing with income. The magnitudes of these parameters are roughly consistent with the differences in the mean preferences for test scores between lunch-recipients and non-lunch recipients within race. Similarly, the mean preference for school scores is increasing in the student's baseline test score. The coefficient on the interaction between the student's baseline test score and the school mean test score is positive - implying that those with higher test scores relative to their baseline peer group value a school's test scores more. The effect of a student's baseline score on the preference for school test scores is similar in magnitude to the effect of income. A one standard deviation increase in the baseline test score is associated with a 0.3-0.6 increase in the mean preference for school test scores, while a one standard deviation increase in neighborhood income (about $\$ 25,000$ ) is associated with a $0.3-0.4$ increase in the mean preference for school test scores.

The coefficients on the interactions of income and baseline score with school scores demonstrate that preferences for school test scores vary considerably with observable characteristics. Parameter estimates for the standard deviation in idiosyncratic preferences for academics are reported in Row 2. While differences in baseline test scores and income each generate a standard deviation in preferences of roughly 0.3-0.6 based on the calculations from the previous paragraph, the estimated standard deviation in idiosyncratic preferences for school test scores is also around 0.3 for non-whites and 0.65 for whites. Hence, there is substantial unobserved heterogeneity in preferences for test

\footnotetext{
${ }^{17}$ For students who are eligible for lunch subsidies, we did not include the interaction with neighborhood income because all of these students are presumably very low income. In initial specifications using a conditional logit, income interactions with the preference for school scores were generally insignificant for the lunch-recipient segments.

${ }^{18}$ Recall that both neighborhood income and the student's baseline score are "de-meaned", so that the coefficient on the main effect of school score measures the value of school test score for a student with average income and baseline test score (both equal to zero).
} 
scores. The substantial variation across students in the weight placed on academics suggests that we may expect to see strong school choice selection on academic outcomes for some students and not for others. The fact that much of the heterogeneity in preferences is unobservable implies that the traditional approach of allowing the treatment effect to vary with observable characteristics, such as race or lunch status, may not completely capture heterogeneous treatment effects by preferences for academics.

The parameter estimates for the remaining coefficients indicate that parents face important trade-offs between academic and non-academic factors when choosing schools. Rows 5 and 6 report the parameter estimates for the lognormal distribution of preferences for distance. Rows 7 and 8 report the mean preference and standard deviation for the neighborhood (or 'home') school. ${ }^{19}$ Parents dislike distance and prefer their neighborhood school. These coefficients indicate that the average parent must trade-off utility for proximity in order to gain utility from expected academic outcomes. For most students, attending a high-achieving school will require them to choose a school that is farther than their home school and a school that is not their home school. Hence there is a negative correlation between school characteristics that measure proximity and those that capture academic achievement. This implies that parents of all races must, on average, trade-off utility for academic gains against utility gains for proximity.

In addition to trading-off proximity for academics, African American parents must trade-off academic gains against the racial composition of peers. The preference coefficients on percent black imply that the average African American parent prefers schools where approximately $70 \%$ of the student body population is black (the peak of the mean quadratic preference for race), while the district as a whole is approximately 45\% African American. However, the percent black at a school is negatively correlated with average test scores (correlation is around -0.65). The negative correlation between test scores and racial composition implies that African American parents must value academic achievement much more than their white counterparts in order to induce them to choose a higher performing school that also has, on average, fewer African American

\footnotetext{
${ }^{19}$ Hastings et al. (2006a) discuss the interpretation of the neighborhood school. They test if this coefficient represents a non-linearity in the preference for proximity or if it is potentially consistent with a default effect. They provide evidence that the preference for the neighborhood school is a neighborhood preference that is not generated by default behavior.
} 
students. Given the coefficients for the quadratic term in racial preferences, the loss in utility for black families is highest when percent black is low (less than $40 \%$ ), which is precisely the range in which school average test scores are highest.

Based on the estimates in Table III, we used (8) to calculate a posterior estimate of the weight that each parent placed on academics when choosing schools for their child. Table IV reports the means and standard deviations for these posterior weights by the four demographic subgroups used in TableIII. There is considerable variation in these posterior weights in our sample, with a standard deviation that is more than one half of the sample mean $(0.845$ versus 1.348$)$. The mean posterior weights vary across demographic subgroups as expected: however, there is also considerable variation in the posterior weights within each subgroup. This implies that parents' reasons for choosing a school can differ substantially across race and lunch subsidy status; two prominent baseline characteristics focused on in the prior literature.

\section{Estimating the Impact of Attending a $1^{\text {st }}$ Choice School on Academic Achievement}

In this section we estimate the effect of attending a $1^{\text {st }}$ choice school on academic achievement, and examine how it varies across subgroups and with the estimated weight parents placed on test scores when choosing a school. We focus on the subset of students choosing schools that were over-subscribed and limit our sample to the marginal priority groups within those schools for whom lottery number alone determined initial admission. We ignore members of priority groups in which all students were either admitted or denied admission - since the assignment of lottery numbers had no impact on their admission status. This allows us to use the random admission of students into a school, conditional on the school they chose. ${ }^{20}$

We began with the choice forms submitted by 105,706 students in the first year. ${ }^{21}$ After dropping students who were not in grades 4-8, who had special disabilities needs,

\footnotetext{
${ }^{20}$ In some schools, the marginal priority group will consist of those who attended the school the year before, or free-lunch eligible students, or students from the choice zone. The marginal priority group may also be different for different grade levels in a school.

${ }^{21}$ Reflecting the district's intensive outreach efforts, choice forms were received for over $95 \%$ of all the students enrolling that fall.
} 
and students who were admitted because of siblings, we were left with a sample of 37,115 . Of these, 22,872 listed their guaranteed home school $(n=19,669)$ or magnet continuation school $(n=3,203)$ and, therefore, were not subject to randomization. Another 7,583 students were in groups sufficiently high on the priority list that they were not subject to the randomization. There were 3,065 students in marginal priority groups, described above as those priority groups within the schools where slots were allocated on the basis of a random number. Finally, there were 3,595 students in priority groups that were sufficiently low on the priority list that all members of the priority group were denied admission and placed on the waitlist.

Table V compares descriptive statistics on the baseline characteristics of students in the marginal priority group to other students in the district. Overall, students in the marginal priority group appear to be fairly representative of students who chose a nonguaranteed school. The only notable differences are that the marginal priority group was more likely to be eligible for lunch subsidies than the waitlisted group (reflecting the priority given to eligible students), and applied to schools with higher test scores than did the admitted group (reflecting capacity constraints at schools with higher test scores). Not surprisingly, students choosing non-guaranteed schools differed from students who chose a guaranteed school: they had home schools with lower test scores and higher proportions of minority and lunch-eligible students, and were more likely to minority, poor, and doing poorly in school themselves. Thus, the marginal priority group should provide a reasonable estimate of the impact of attending one's first choice school for a typical student who chose a non-guaranteed school (i.e., treatment on the treated). In addition, the final row in Table $\mathrm{V}$ shows the mean weight placed on academics $\left(\hat{\beta}_{i}^{A}\right)$ for students in the marginal priority group versus other students in the district. The mean $\hat{\beta}_{i}^{A}$ for students in the randomized group is very similar to that for students in the district as a whole. $^{22}$

Within the marginal priority groups, we want to estimate the impact of attending a first-choice school on academic outcomes using:

\footnotetext{
${ }^{22}$ The low mean weight for students in the admitted group is consistent with the fact that these students were typically choosing lower-scoring and capacity unconstrained schools, as can be seen from the differences in sample means for the Average Combined Scores of the chosen school (row 8 in Table V).
} 


$$
Y_{i j}=X_{i} \alpha+\gamma_{1} \text { Attended } 1 \text { stChoice }_{i j}+\delta_{j}+\varepsilon_{i j}
$$

where $X_{i}$ includes student baseline characteristics and $\delta_{\mathrm{j}}$ are school lottery fixed-effects. Our controls include: gender, race/ethnicity, free lunch status, home school dummy variables, baseline test scores, income, absences, suspensions, and grade retentions. The fixed effects, $\delta_{j}$, are included for each school and grade, to account for the fact that the probabilities of winning the lottery varied across lotteries (Rouse 1998). Our outcomes of interest, $Y_{i j}$, include absences, suspensions, and standardized test scores. In addition the testing data in North Carolina also includes student self-reports on the number of hours of home work they did each week, and we include this as an outcome as well. Since not all of those who won the lotteries actually chose to attend their first choice school, and some of those who lost the lotteries were subsequently admitted off the waiting lists, we used the randomized lottery outcome as an instrument for attending a first choice school. Random assignment by lottery implies that the impact of winning the lottery, $\gamma_{1}$, is consistently estimated even without these control variables, but the additional control variables greatly improve precision. We report robust standard errors, allowing for correlations in outcomes among students with the same first-choice school (which may include more than one grade with a lottery).

To verify that winning the school lottery was truly random within the marginal priority group, we examine whether the baseline characteristics of lottery winners and losers differ in our estimation sample. Our estimation sample excludes 181 students who were in marginal priority groups but missing needed baseline characteristics such as address (which was used in the choice model). Table VI reports mean baseline characteristics for lottery winners and losers, as well as adjusted differences from an OLS regression that included fixed effects for the school program and grade for which the lottery was conducted. All of the differences in baseline characteristics were small and not significantly different from zero, verifying that lottery assignment was independent of student characteristics in our sample.

Table VII shows reduced form estimates of the impact of winning the lottery on attrition and the characteristics of the school attended. These reduced form regressions used a specification identical to (9), but replacing the indicator for attending a first choice school with an indicator for winning the lottery. The first row shows that lottery winners 
were 53 percentage points more likely to attend their first choice school than the lottery losers. ${ }^{23}$ The second row gives the effect of winning the lottery on whether or not the student was enrolled in any CMS school in the 2002-2003 school year. This estimate shows that there was no differential attrition across lottery winners and lottery losers. ${ }^{24}$ The remaining rows show that students who won the lottery attended schools with approximately one-tenth of a student-level standard deviation higher test scores, and seven percent fewer students who were eligible for lunch subsidies.

Table VIII presents the results from the instrumental variables regression in (9) on measures of academic outcomes. Among these outcome measures, the average treatment effect is significant and negative for retention rates. Winning the lottery to attend a first choice school led to a reduction in retentions - a 2.3 percentage point decrease of an average base of $2.2 \%$. However, we do not find a significant impact on absences or suspensions. In addition, we find that students who are randomized into their first choice school report spending more time on homework. The outcome measure is an indicator if the student reports spending more than 3 hours per week on homework on self-reported surveys given to students with the End of Grade exams. Even though students who attend their first choice school report a significant increase in homework hours, we find no measurable average effect on standardized test scores. The final row of estimates in Table VIII shows no significant impact of attending a first choice school on standardized test scores. ${ }^{25}$ The point estimate is nearly zero, but there is a relatively large standard error.

\section{Heterogeneous Treatment Effects on Test Score Outcomes}

Table IX shows estimates of the average treatment effect on student test scores in various subgroups of students defined on the basis of student demographics or

\footnotetext{
${ }^{23}$ This is the first stage regression for the instrumental variables regression of the impact on test scores of attending a first choice school. This estimate is not equal to 100 percent for two reasons: first, some of those who were given the opportunity to attend their first choice did not do so and, second, some of those who were originally waitlisted at their first choice were subsequently called off the waitlist. Overall, approximately $75 \%$ of lottery winners and $25 \%$ of lottery losers attended their first choice school.

${ }^{24}$ Average attrition rates were fairly low at $9.8 \%$, and consistent with estimates of inter-county mobility rates from the Census. The estimated effect of winning the lottery on attrition is small in size $(-0.018)$ and not significantly different than zero, indicating that there was no significant differential attrition by the end of the 2002-2003 school year.

${ }^{25}$ Regression estimates show the same effect on math and reading scores when run separately, so we use the combined score to improve precision.
} 
characteristics of the school chosen. Prior studies have used these subgroups of students who on a priori grounds may have different underlying reasons for choosing schools that may be correlated with the expected treatment effect. Estimates for most of the subgroups remain insignificant. However, the estimated treatment effect is positive and significant for two of the subgroups (whites, and students with above median income) and there is an apparent pattern of positive treatment effects for higher SES students and students applying to higher-scoring schools.

The pattern of subgroup impacts is strongly related to the average weight $\left(\hat{\beta}_{i}^{A}\right)$ that parents place on school test scores. Columns 3 and 4 of Table IX report the mean $\hat{\beta}_{i}^{A}$ and its standard deviation, respectively, for students in each of the subgroups. There is a positive correlation between $\hat{\beta}_{i}^{A}$ and the estimated subgroup impacts across each of the subgroups. Figure 2 plots the subgroup estimates from Table IX against the mean $\hat{\beta}_{i}^{A}$ for each subgroup. The strong positive correlation between the two (correlation=0.89) suggests that differences in impacts across subgroups may be generated by differences in the underlying determinants of choice, but the large variation in $\hat{\beta}_{i}^{A}$ within each subgroup reported in Table IX, suggests that subgroup impacts may be insignificant if differences in the weights parents place on academics are driving heterogeneous treatment effects.

This evidence highlights three advantages of using estimates of $\hat{\beta}_{i}^{A}$ to identify heterogeneous treatment effects over subgroup estimation based on observables such as race and income. First, using a single index, rather than estimating differences in impacts for an arbitrary number of subgroups, increases the precision with which we can identify heterogeneous treatment effects by exploiting all of the within and between subgroup variation in preferences. Second, the $\hat{\beta}_{i}^{A}$ incorporate information on the choice set, distinguishing between students who pick a good school because it is convenient versus students who pick it for its academics. Third, the $\hat{\beta}_{i}^{A}$ give us an economic interpretation for subgroup impacts, allowing us to evaluate the impact of school choice outside of the estimation sample, and to potentially design school choice plans that address differences 
in the underlying drivers of parental choice (Hastings et al. (2007), Hastings and Weinstein (2007)).

We therefore allow the impact of attending a first choice school on standardized test scores to vary explicitly with $\hat{\beta}_{i}^{A}$ by estimating:

$$
Y_{i j}=X_{i} \alpha+\gamma_{1} \text { Attended } 1 \text { stChoice }_{i j}+\gamma_{2} \text { Attended } 1 \text { stChoice }_{i j} * \hat{\beta}_{i}^{A}+\delta_{j}+\varepsilon_{i j}
$$

We estimate (10) by instrumental variables, using winning the lottery and winning the lottery interacted with $\hat{\beta}_{i}^{A}$ as instruments, and adding $\hat{\beta}_{i}^{A}$ as a control variable. Note that all of the information used to derive the preference weights was observed prior to randomization. Since $\hat{\beta}_{i}^{A}$ depends only on baseline data that is independent of whether the student won the lottery, its interaction with winning the lottery is a valid instrument once one has conditioned on baseline data. Finally, note that coefficient estimates for terms involving $\hat{\beta}_{i}^{A}$ are not attenuated by the usual measurement error bias - the measurement error $\left(\beta_{i}^{A}-\hat{\beta}_{i}^{A}\right)$ is uncorrelated with the posterior estimate $\hat{\beta}_{i}^{A}$ by construction (Hyslop and Imbens (2001)). The results from (10) are presented in Table X.

The coefficients imply that the effect of attending one's first choice school on a student's test scores is significantly increasing with the weight that a student placed on test scores in choosing a school. The regression estimates imply that a one standard deviation increase in the weight that an individual places on school test scores raises the treatment effect on the student's own test score by 0.062 standard deviations. For students who place no weight on test scores in their school choice, the coefficient on attending one's first-choice school implies a negative (although not significant) treatment effect - their test scores fall by 0.105 standard deviations if they attend their first-choice school. These estimates imply a small negative impact (-0.002 standard deviation score gain) of attending a first-choice school on test scores for an average student with a $\hat{\beta}_{i}^{A}$ of 1.34, and a large positive effect on test scores (about 0.10 ) for students at the $95^{\text {th }}$ percentile of the $\hat{\beta}_{i}^{A}$ distribution.

A 0.1 standard deviation increase in a student's test score results is equivalent to a 3-4 percentile rank gain in test scores. Child development psychologists suggest that a 5 percentile rank gain in a student's test score translates into a significant cognitive gain in 
academic aptitude. Alternatively, estimates of the impact that test scores have on future earnings suggest that a 0.1 standard deviation in increase in test scores is worth $\$ 10,000$ to $\$ 20,000$ in net present value of future earnings (Kane and Staiger (2002)).

\section{Parents Who Face Significant Tradeoffs}

These estimates are consistent with our general prediction that students with high $\hat{\beta}_{i}^{A}$ should have a positive expected treatment effect (gain in academic achievement from attending the first-choice school). However, the treatment effect for a student with low $\hat{\beta}_{i}^{A}$ (near zero) is theoretically ambiguous and depends on whether parents face tradeoffs - if expected academic achievement is negatively correlated with other valued school characteristics. Since the percent black at a school is negatively correlated with average test scores in CMS schools (correlation is around -0.65), the racial composition of a school is an important trade-off that many African American parents face. We estimate (from the mixed logit results) that the average African American parent prefers schools where approximately $70 \%$ of the student population is black. Parents that prefer a school with a high proportion of African American students must value academic achievement more in order to induce them to choose a higher performing school that also has, on average, fewer African American students. Thus, all students with strong academic preferences (high- $\hat{\beta}_{i}^{A}$ ) will have a positive gain in academic achievement from attending the first choice school, but among students with weak academic preferences (low- $\hat{\beta}_{i}^{A}$ ) we might expect a negative treatment effect among students that prefer a school with a high proportion African American. In other words, the interaction effect between $\hat{\beta}_{i}^{A}$ and winning the school choice lottery should have a negative intercept and a steeper slope for students who have strong preferences for predominantly African American schools.

Table XI presents the results from specifications identical to those in Table X, but estimated separately for students who prefer a school that is less than 55 percent black (primarily white students) and students of parents who prefer a school that is more than 55 percent black (primarily non-white students). Posterior estimates of student-level preferences for school racial composition were calculated in the same way as the $\hat{\beta}_{i}^{A}$ 's 
were. The average treatment effect is positive for students who prefer a predominantly white school, and there is no significant interaction with the weight that the student places on test scores in their school choice. Among students of parents who prefer

predominantly white schools, both relatively high- and low- $\hat{\beta}_{i}^{A}$ students experience academic gains from attending their first choice school. In contrast, for students of parents who prefer a predominantly black school there is a significant interaction between their estimated preference for academics and the treatment effect. High- $\hat{\beta}_{i}^{A}$ students experience academic gains from attending their first choice school that are similar to students who prefer a predominantly white school. In contrast, low- $\hat{\beta}_{i}^{A}$ students who prefer a predominantly black school experience a negative effect on academic performance from attending their first choice school. This evidence suggests that the relationship between preferences and treatment effects may depend importantly on the trade-offs that parents face given their preferences and their school choice options. These results also highlight the potential importance of the underlying decision-making process to understanding the heterogeneous impacts that public school choice has on student academic outcomes.

\section{Schools versus Student-school Interactions}

Our results show that the school one attends has a causal impact on student academic outcomes, but not all parents choose a school that maximizes their child's academic gains. Students of parents who choose schools primarily based on academic characteristics are able to get those gains from attending their chosen schools. An interesting secondary question is whether all students (even those students whose parents put little weight on academics) would gain academically from attending these same schools. Do students of parents who place a high weight on academics simply choose better schools in the sense that any student attending such a school would receive a positive treatment effect? If so, efforts to identify these schools and steer students towards them may increase the impact of school choice on academic outcomes. Alternatively, academic gains may be student-school specific, with the impact of attending a school depending on the student's ability to gain academically at that school. 
In this case, students whose parents choose for academic achievement at a particular school will have gains in academics that students whose parents chose the same school for convenience will not.

In Table XII, we investigate the extent to which the heterogeneity in treatment effects associated with individual preferences for academics can be explained by characteristics of the school chosen (suggesting common school quality). The first column of the table replicates the base estimates for comparison. The next two columns add an interaction to allow the treatment effect to depend on the difference in average test scores between the $1^{\text {st }}$-choice school and the home school. This interaction is insignificant on its own, and has no impact on the interaction with $\hat{\beta}_{i}^{A}$, suggesting that the gap in test scores in not a good indicator of the likely treatment effect. Columns 4 and 5 add an interaction with the average test score in the $1^{\text {st }}$-choice school (not relative to the home school), and the results are similar. Since average test scores may be a poor proxy for academic quality of a school, the remaining columns of the table try interacting the treatment with the average weight $\left(\hat{\beta}_{i}^{A}\right)$ among all students participating in the school's lottery (a high average indicates the school attracts students who care about academics) and a full set of school effects (allowing each school to have its own average impact on student outcomes). In both of these specifications, we find no significant evidence of heterogeneity in treatment effects across schools, and the coefficient on the interaction with $\hat{\beta}_{i}^{A}$ is little changed (although the standard errors are larger).

Overall, the heterogeneity in treatment effects associated with individual preferences for academics do not appear to be explained by characteristics of the school chosen, although the estimates are not very precise. The general pattern of results suggests that student and school interactions play a more important role in determining academic outcomes.

\section{Conclusion}

When given the choice to attend a public school other than the home school to which they have been assigned, the parents of 49 percent of the students in Charlotte took 
the opportunity and listed a school other than their assigned school as a first choice. In this paper, we evaluate the impact of switching schools on various academic and nonacademic outcomes. On average, among those applying to the oversubscribed schools, winning the lottery had no discernable impact on students' own reading and math scores overall, even though lottery winners attended schools with higher math and reading scores than did lottery losers. Winning the lottery had only modest impacts on other outcomes, such as increasing homework time and reducing grade retentions.

However, parents seem to choose schools for many different reasons. Indeed, one quarter of parents were willing to switch chose schools with lower mean test scores than their assigned schools. Overall, the results presented in this paper imply that the impact of attending one's first choice school on academic outcomes is significantly increasing with the value that students parents placed on test scores when choosing a school. Students of parents who placed a high weight on school test scores experienced gains in tests scores as a result of attending the first-choice school. In contrast, students of parents who placed a low weight on school test scores experienced (insignificant) declines in test scores as a result of attending their first-choice school.

A number of recent papers have found no impact on average of attending a firstchoice school on academic achievement. Our evidence suggests that the absence of any academic gains on average does not imply that school choice is ineffective. On the contrary, parents appear to get what they want. When parents want improved academic outcomes, they are able to get them. When parents value other school attributes, and are willing to trade off academic gains for utility gains on other dimensions, school choice will allow them to make that choice - even if maximizing parental utility does not maximize academic achievement. In general the marginal impact of school choice on academic outcomes will depend on both the willingness of parents to make these tradeoffs, and the extent to which the available school choices require such tradeoffs to be made. 


\section{$\underline{\text { References }}$}

Abdulkadiroglu, Atila and Tayfun Sonmez (2003), "School Choice: A Mechanism Design Approach," American Economic Review, 93(3):729-747.

Abdulkadiroglu, Atila, Parag A. Pathak, Alvin E. Roth, and Tayfun Sonmez (2006), "Changing the Boston School Choice Mechanism: Strategy-proofness as Equal Access," working paper, Harvard University.

Altonji J.G., T.E. Elder, C. Taber (2002), "An Evaluation of Instrumental Variable Strategies for Estimating the Effect of Catholic Schools," National Bureau of Economic Research Working Paper No. 9358.

Berry, Steven, James Levinsohn and Ariel Pakes (2004), "Differentiated Products Demand Systems from a Combination of Micro and Macro Data: The New Car Market," Journal of Political Economy, 112(1): 68-105.

Blank, R.K. (1983), Survey of Magnet Schools: Analyzing a Model of Quality Integrated Education. Washington, DC, ABT Associates for the Department of Education,1983.

Bryk, A., V. Lee and P. Holland (1993), Catholic Schools and the Common Good. Cambridge, MA: Harvard University Press, 1993.

Cullen, Julie, Brian Jacob and Steven Levitt (2006), "The Effect of School Choice on Student Outcomes: Evidence from Randomized Lotteries," Econometrica, 74(5):1191-1230.

Coleman, James S., Thomas Hoffer and Sally Kilgore (1982), High School Achievement: Public, Catholic, and Private Schools Compared. New York: Basic Books.

Dagsvik, John K (1994), "Discrete and Continuous Choice, Max-Stable Processes, and Independence from Irrelevant Attributes," Econometrica, 62(5):1179-1205.

Evans, William and Robert Schwab (1995), "Finishing High School and Starting College: Do Catholic Schools Make a Difference?" Quarterly Journal of Economics 110 (4): 941-974.

Gamoran, A. (1996), "Student Achievement in Public Magnet, Public Comprehensive, and Private City High Schools," Educational Evaluation and Policy Analysis 18 (1): $1-18$.

Glazerman, Steven and Robert H. Meyer (1994), "Public School Choice in Minneapolis," in T.A. Downes and W.A. Testa, eds., Midwest Approaches to School Reform. Proceedings of a conference held at the Federal Reserve Bank of Chicago, pp.110-126. 
Green, J. P., P.E. Peterson, and J. Du (1997), "The Effectiveness of School Choice: The Milwaukee Experiment,"_Cambridge, MA, Program on Education Policy and Governance, Harvard University.

Hastings, Justine S., Thomas Kane, and Douglas Staiger (2006a), "Parental Preferences and School Competition: Evidence from a Public School Choice Program," National Bureau of Economic Research Working Paper No.11805, November 2005, revised May 2006.

Hastings, Justine S., Thomas Kane and Douglas Staiger (2006b), "Gender, Performance and Preferences: Do Girls and Boys Respond Differently to School Environment? Evidence from School Assignment by Randomized Lottery," American Economic Review Papers and Proceedings, 96 (2): 232-236.

Hastings, Justine S., Richard Van Weelden, and Jeffrey M. Weinstein (2007), "Preferences, Information, and Parental Choice Behavior in Public School Choice," National Bureau of Economic Research Paper Working Paper No. 12995.

Hastings, Justine S., Jeffrey Weinstein (2007), "No Child Left Behind: Estimating the Impact on Choices and Student Outcomes," National Bureau of Economic Research Paper Working Paper No. 13009

Heckman, James (1997), "Instrumental Variables: A Study of Implicit Behavioral Assumptions Used In Making Program Evaluations," Journal of Human Resources, 32(3):441-462.

Heckman, James J., Jeffrey Smith, and Nancy Clements (1997), "Making the Most Out of Programme Evaluations and Social Experiments: Accounting for Heterogeneity in Programme Impacts," Review of Economic Studies, 64:487-535.

Herckman, Urzua and Vittacil (2006), "Understanding Instrumental Variables in Models with Essential Heterogeneity," Review of Economics and Statistics, 2006, 88(3): 389-432.

Hyslop, Dean R. and Guido W. Imbens (2001), "Bias From Classical And Other Forms Of Measurement Error," Journal of Business and Economic Statistics, 19(4): 475481.

Kane and Steiger (2002), "The Promise and Pitfalls of Using Imprecise School Accountability Measures," Journal of Economic Perspectives, 16(4):91-114, Fall 2002.

Krueger, Alan B. and Pei Zhu (2004), "Another Look at the New York City School Voucher Experiment," American Behavioral Scientist, pp.658-98.

Mayer, Daniel P., Paul E. Peterson, David E. Myers, Christina Clark Tuttle, and William G. Howell (2002), School Choice in New York City After Three Years: An 
Evaluation of the School Choice Scholarships Program. Princeton, NJ: Mathematica Policy Research, Inc.

McFadden, D. and K. Train (2000). "Mixed Multinomial Logit Models for Discrete Response," Journal of Applied Econometrics, 15(5): 447-470.

Neal, D. (1997), "The Effects of Catholic Secondary Schooling on Educational Achievement," Journal of Labor Economics, XV, 98-123.

Peterson, P. E., D. Myers and W. G. Howell (1998), "An Evaluation of the New York City School Choice Scholarship Program: The First Year," Cambridge, MA, Mathematica Policy Research and the Harvard Program on Education Policy and Governance.

Revelt, David and Kenneth E. Train (1998), "Mixed Logit with Repeated Choices: Households' Choices of Appliance Efficiency Level," Review of Economics and Statistics, 80 (4): 647-657.

Rouse, Cecilia. E. (1998), "Private school vouchers and student achievement: An evaluation of the Milwaukee Parental Choice Program," Quarterly Journal of Economics, 113(2):553-602.

Train, Kenneth E. (2003), Discrete Choice Methods with Simulation. Cambridge University Press.

Witte, John F., Troy D. Sterr and Christopher A. Thorn (1995), Fifth-Year Report: Milwaukee Parental Choice Program. Madison, Wisconsin, University of Wisconsin. 
Figure 1: Distribution of Difference in Average Standardized School Score Between Student's First Choice School and Home School.

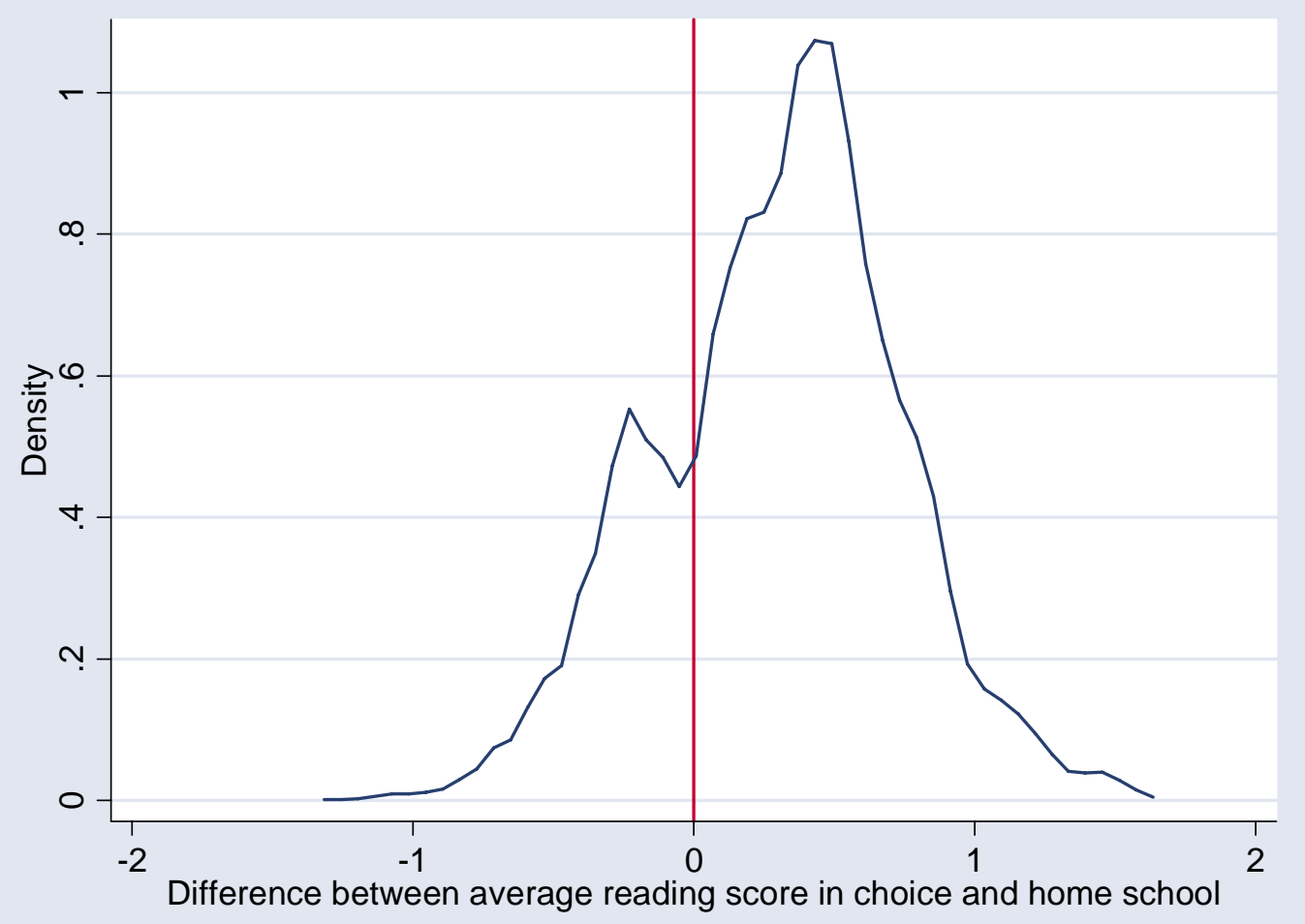


Figure 2. Subgroup Estimates of the Effect of Attending a $1^{\text {st }}$-choice School

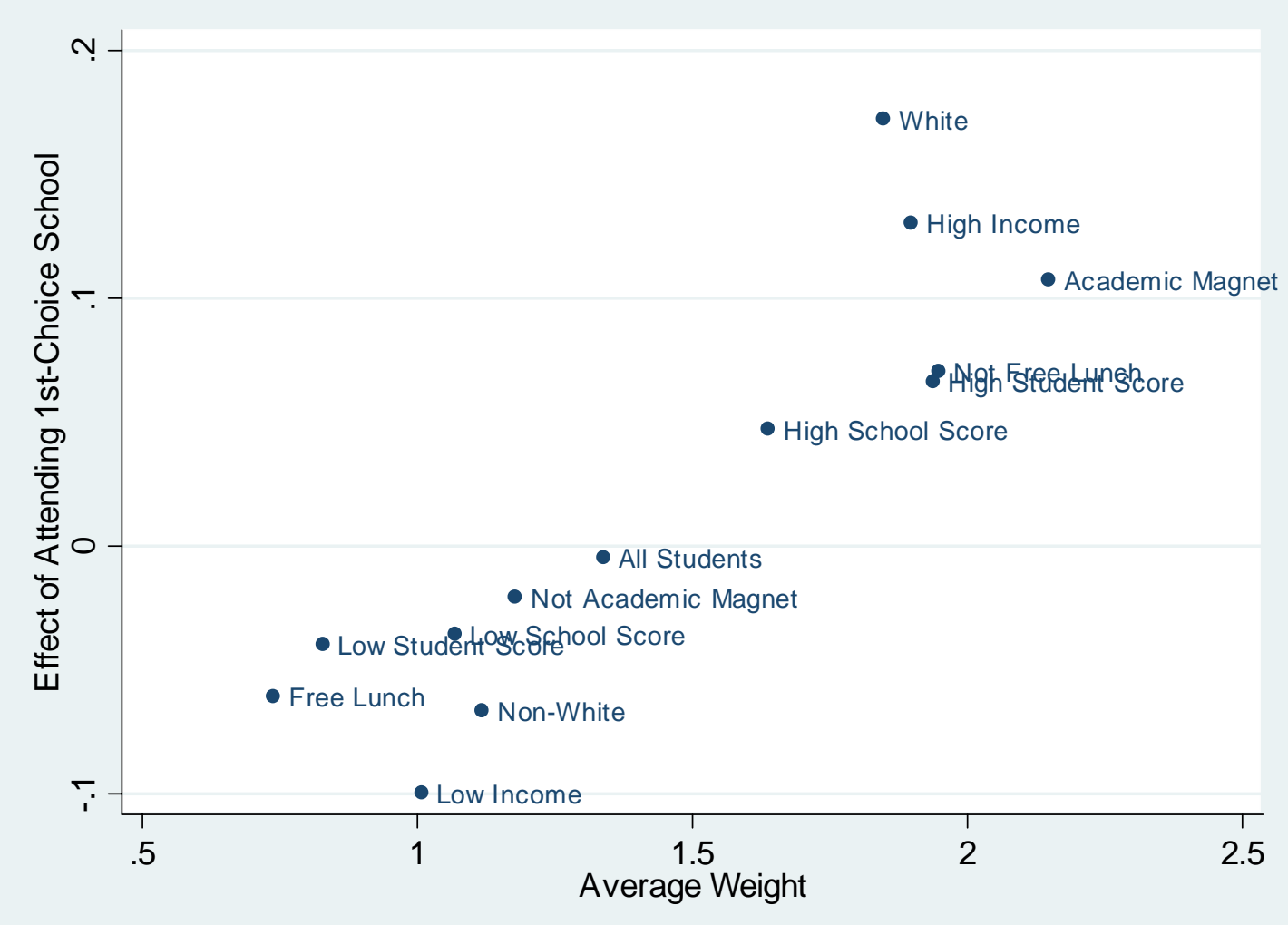


Table I: Key Explanatory Variable Definitions

\begin{tabular}{|c|c|}
\hline Variable & Description \\
\hline Distance & $\begin{array}{l}\text { Driving distance from student } i \text { to school } j \text { calculated } \\
\text { using MapInfo with Census Tiger Line files. }\end{array}$ \\
\hline School Score & $\begin{array}{l}\text { Average of the student-level standardized scale score for } \\
\text { students in school } j \text { on math and reading End of Grade exams for } \\
\text { the } 2002-2003 \text { school year. This is the average of the test score } \\
\text { variable described below across all students in school } j \text {. }\end{array}$ \\
\hline Test Score & $\begin{array}{l}\text { The sum of student } i \text { 's scale score on End of Grade math and } \\
\text { reading exams in baseline year 2001-2002 standardized by the } \\
\text { mean and standard deviation of district-wide scores for students } \\
\text { in his or her grade. }\end{array}$ \\
\hline Income & $\begin{array}{l}\text { The median household income reported in the } 2000 \text { Census } \\
\text { for households of student i's race in student i's block group. } \\
\text { Income is demeaned by the county-wide average of } \\
\text { approximately } \$ 51,000 \text { and is reported in thousands of dollars. }\end{array}$ \\
\hline Percent Black & $\begin{array}{l}\text { The percent of students in school } j \text { who are black according } \\
\text { to } 2002-2003 \text { school year administrative data. }\end{array}$ \\
\hline
\end{tabular}

Table II: Key Explanatory Variable Summary Statistics

\begin{tabular}{|lllrrr|}
\hline Summary Statistics Using First Choice Data & \multicolumn{4}{l|}{ Max } \\
\hline \hline Variable & Obs. & Mean & Std. Dev. & \multicolumn{1}{l|}{ Min } & \multicolumn{1}{c|}{ Max } \\
Distance & 2434113 & 13.0071 & 6.7254 & 0.0010 & 42.4069 \\
School Score & 2434113 & -0.1087 & 0.4487 & -0.9537 & 1.9478 \\
Test score & 2434113 & 0.0567 & 0.9886 & -2.9113 & 3.0255 \\
Income & 2434113 & 5.1226 & 27.5669 & -48.5010 & 149.0010 \\
Percent Black & 2434113 & 0.5252 & 0.2507 & 0.0584 & 0.9801 \\
\hline
\end{tabular}


Table III: Estimates from Mixed Logit Model

\begin{tabular}{|c|c|c|c|c|c|}
\hline & & \multicolumn{4}{|c|}{ Parameter Estimates* } \\
\hline & & \multicolumn{2}{|c|}{$\begin{array}{c}\text { Not Receiving Lunch } \\
\text { Subsidies }\end{array}$} & \multicolumn{2}{|c|}{$\begin{array}{l}\text { Receiving Lunch } \\
\text { Subsidies }\end{array}$} \\
\hline Variable & Parameter & "White & Black & White & Black \\
\hline \multicolumn{6}{|l|}{ Preferences for Scores } \\
\hline School Score & Mean & 1.1732 & 1.8035 & 0.3671 & 0.9396 \\
\hline \multirow[t]{2}{*}{ Income*School Score } & Mean & 0.0151 & $\begin{array}{l}0.2088 \\
0.0126\end{array}$ & -- & -- \\
\hline & \multicolumn{4}{|c|}{ Baseline own score * } & -- \\
\hline \multirow[t]{2}{*}{ School Score } & Mean & 0.5558 & 0.5734 & 0.2924 & 0.4995 \\
\hline & Std. Dev. & -- & -- & -- & -- \\
\hline \multirow[t]{2}{*}{ Distance** } & Mean & -0.3526 & -0.2684 & -0.3784 & -0.2751 \\
\hline & Std. Dev. & 0.0684 & 0.0413 & 0.1273 & 0.0639 \\
\hline \multirow[t]{2}{*}{ Home School } & Mean & 2.1300 & 1.7373 & 1.9816 & 1.7710 \\
\hline & Std. Dev. & 0.5130 & 0.6799 & 0.8248 & 0.7752 \\
\hline \multicolumn{6}{|l|}{ Preferences for Race } \\
\hline \multirow[t]{2}{*}{ Percent Black } & Mean & 3.3068 & 5.1340 & 1.9268 & 3.1409 \\
\hline & Std. Dev. & 2.6417 & 1.6447 & 2.0795 & 0.8745 \\
\hline \multirow[t]{2}{*}{ Percent Black Sqaured } & Mean & -5.4580 & -3.6790 & -3.5385 & -2.3005 \\
\hline & Std. Dev. & -- & -- & -- & -- \\
\hline \multicolumn{6}{|l|}{ Implied Mean } \\
\hline \multirow[t]{2}{*}{ Preferred \% Black } & & 0.3029 & 0.6977 & 0.2723 & 0.6827 \\
\hline & Std. Dev. & 0.2420 & 0.2235 & 0.2938 & 0.1901 \\
\hline \multicolumn{6}{|l|}{ Other Preferences } \\
\hline \multirow{2}{*}{ Last-year School } & Mean & 3.7941 & 3.3837 & 3.5016 & 2.8495 \\
\hline & Std. Dev. & 2.4977 & 2.7896 & 3.4651 & 3.3825 \\
\hline \multirow[t]{2}{*}{ Choice Zone (busing) } & Mean & 1.1909 & 1.2484 & 1.9203 & 1.6132 \\
\hline & Std. Dev. & 0.8285 & 1.2418 & 1.5083 & 1.2442 \\
\hline \multicolumn{6}{|c|}{ Estimated Correlation Coefficients: } \\
\hline \multicolumn{2}{|c|}{ Corr(Distance, School Score) } & 0.4939 & -0.1055 & 0.3379 & -0.6355 \\
\hline \multicolumn{2}{|c|}{ Corr(Distance, Home School) } & -0.0788 & 0.0007 & -0.2623 & -0.1122 \\
\hline \multicolumn{2}{|c|}{ Corr(School Score, Home School) } & -0.7888 & -0.6016 & -0.8411 & -0.5895 \\
\hline
\end{tabular}

* All estimates are significant at the $1 \%$ level or higher

** Distribution of preference on distance follows a log normal distribution. 
Table IV: Summary Statistics of Posterior Weight Placed On Academics when Choosing a School

\begin{tabular}{|c|c|c|c|c|c|}
\hline & \multirow[b]{2}{*}{ All Students } & \multicolumn{2}{|c|}{$\begin{array}{c}\text { Not Receiving } \\
\text { Lunch Subsidies }\end{array}$} & \multicolumn{2}{|c|}{$\begin{array}{c}\text { Receiving } \\
\text { Lunch Subsidies }\end{array}$} \\
\hline & & White & Black & White & Black \\
\hline Mean & 1.348 & 1.872 & 1.746 & 0.343 & 0.632 \\
\hline Standard Deviation & 0.845 & 0.676 & 0.598 & 0.381 & 0.448 \\
\hline $10^{\text {th }}$ Percentile & 0.256 & 1.005 & 0.994 & -0.121 & 0.052 \\
\hline Median & 1.320 & 1.882 & 1.729 & 0.320 & 0.621 \\
\hline $90^{\text {th }}$ Percentile & 2.461 & 2.700 & 2.515 & 0.838 & 1.221 \\
\hline
\end{tabular}

Table V: Comparison of Student Characteristics

\begin{tabular}{|c|c|c|c|c|c|}
\hline & All & $\begin{array}{c}\text { Chose } \\
\text { Guaranteed }\end{array}$ & Chose & Non-guarantee & School \\
\hline & Students & School & Admitted & Randomized & Waitlisted \\
\hline Student demographics & & & & & \\
\hline Black & $44.3 \%$ & $34.6 \%$ & $62.5 \%$ & $59.7 \%$ & $54.8 \%$ \\
\hline Free or reduced lunch & $39.2 \%$ & $31.3 \%$ & $60.3 \%$ & $51.3 \%$ & $34.3 \%$ \\
\hline Student's prior year performance & & & & & \\
\hline Reading test score (SD units) & 0.02 & 0.15 & -0.26 & -0.09 & -0.11 \\
\hline Math test score (SD units) & 0.02 & 0.16 & -0.26 & -0.12 & -0.15 \\
\hline Absent 18 or more days & $8.5 \%$ & $6.8 \%$ & $11.7 \%$ & $10.8 \%$ & $10.7 \%$ \\
\hline Retained & $1.5 \%$ & $1.2 \%$ & $2.0 \%$ & $1.9 \%$ & $1.9 \%$ \\
\hline Suspended & $12.2 \%$ & $9.3 \%$ & $17.7 \%$ & $16.5 \%$ & $15.4 \%$ \\
\hline Choice school characteristics & & & & & \\
\hline Average combined scores & 0.05 & 0.09 & -0.09 & 0.08 & 0.10 \\
\hline Percent free or reduced lunch & $40.6 \%$ & $38.6 \%$ & $50.9 \%$ & $36.6 \%$ & $35.6 \%$ \\
\hline Percent black or hispanic & $49.4 \%$ & $46.2 \%$ & $59.8 \%$ & $50.0 \%$ & $47.0 \%$ \\
\hline Home school characteristics & & & & & \\
\hline Average combined scores & -0.08 & 0.03 & -0.28 & -0.23 & -0.27 \\
\hline Percent free or reduced lunch & $47.0 \%$ & $40.7 \%$ & $59.3 \%$ & $53.3 \%$ & $56.0 \%$ \\
\hline Percent black or hispanic & $53.6 \%$ & $47.1 \%$ & $65.3 \%$ & $61.6 \%$ & $63.8 \%$ \\
\hline School assignment & & & & & \\
\hline Assigned to 1 st choice & $85.4 \%$ & $100.0 \%$ & $100.0 \%$ & $40.4 \%$ & $0.0 \%$ \\
\hline Assigned to guaranteed school & $72.5 \%$ & $100.0 \%$ & $0.0 \%$ & $44.6 \%$ & $74.5 \%$ \\
\hline School attendance 02-03 & & & & & \\
\hline Attended 1st choice & $78.7 \%$ & $92.1 \%$ & $81.6 \%$ & $45.4 \%$ & $16.2 \%$ \\
\hline Attended home school & $58.8 \%$ & $79.4 \%$ & $9.7 \%$ & $35.0 \%$ & $51.3 \%$ \\
\hline Posterior Weights & & & & & \\
\hline Weight Placed on Academics - $\hat{\beta}_{i}^{A}$ & 1.36 & 1.44 & 1.09 & 1.33 & 1.39 \\
\hline Number of students & 37115 & 22872 & 7583 & 3065 & 3595 \\
\hline
\end{tabular}

Notes: Data from Charlotte-Mecklenberg Schools (CMS). Sample includes all students in grades 4-8 who applied to a regular or magnet school as their $1^{\text {st }}$ choice for the 2002-2003 school year and were enrolled in CMS in the 2001-2002 school year. Students guaranteed placement because of siblings or in ESL are excluded. 
Table VI: Baseline Characteristics by Treatment and Control Group

\begin{tabular}{|c|c|c|c|c|}
\hline Variable & Admitted & Waitlisted & Difference & $\begin{array}{l}\text { Adjusted } \\
\text { Difference } \\
\end{array}$ \\
\hline \multicolumn{5}{|l|}{ Student demographics } \\
\hline Black & 0.614 & 0.585 & $\begin{array}{c}0.030 \\
(0.067)\end{array}$ & $\begin{array}{c}0.011 \\
(0.022)\end{array}$ \\
\hline Free or reduced lunch & 0.467 & 0.531 & $\begin{array}{l}-0.064 \\
(0.078)\end{array}$ & $\begin{array}{l}-0.015 \\
(0.012)\end{array}$ \\
\hline $\begin{array}{l}\text { Median income ( } \$ 1000 \text { s) by race } \\
\text { and block-group in } 2000 \text { census }\end{array}$ & 48.4 & 49.4 & $\begin{array}{l}-1.0 \\
(3.6)\end{array}$ & $\begin{array}{l}-0.7 \\
(0.7)\end{array}$ \\
\hline \multicolumn{5}{|l|}{ Student's prior year performance } \\
\hline Reading test score & -0.127 & -0.069 & $\begin{array}{c}-0.058 \\
(0.110)\end{array}$ & $\begin{array}{c}-0.025 \\
(0.031)\end{array}$ \\
\hline Math test score & -0.135 & -0.113 & $\begin{array}{c}0.023 \\
(0.106)\end{array}$ & $\begin{array}{c}0.025 \\
(0.030)\end{array}$ \\
\hline Absent 18 or more days & 0.097 & 0.106 & $\begin{array}{l}-0.009 \\
(0.013)\end{array}$ & $\begin{array}{l}-0.007 \\
(0.016)\end{array}$ \\
\hline Suspended & 0.152 & 0.162 & $\begin{array}{l}-0.010 \\
(0.028)\end{array}$ & $\begin{array}{l}-0.022 \\
(0.015)\end{array}$ \\
\hline Retained & 0.019 & 0.018 & $\begin{array}{c}0.001 \\
(0.005)\end{array}$ & $\begin{array}{c}0.001 \\
(0.006)\end{array}$ \\
\hline \multicolumn{5}{|l|}{ Home school characteristics } \\
\hline Average combined score & -0.241 & -0.213 & $\begin{array}{l}-0.028 \\
(0.051)\end{array}$ & $\begin{array}{c}0.003 \\
(0.013)\end{array}$ \\
\hline Percent free or reduced lunch & 0.543 & 0.524 & $\begin{array}{c}0.019 \\
(0.034)\end{array}$ & $\begin{array}{c}0.001 \\
(0.007)\end{array}$ \\
\hline Percent black & 0.625 & 0.607 & $\begin{array}{c}0.018 \\
(0.036)\end{array}$ & $\begin{array}{l}-0.003 \\
(0.007)\end{array}$ \\
\hline Number of students & 1175 & 1709 & 2884 & 2884 \\
\hline
\end{tabular}

Notes: Sample limited to students in randomized priority groups with complete baseline data. Difference is between students admitted (won the lottery) and waitlisted (did not win the lottery). Each adjusted difference is from a separate regression of the given baseline characteristic on whether the student was randomly assigned to her first-choice school, controlling for lottery fixed effects. Standard errors adjust for clustering at the level of the first-choice school. Asterisks indicate significance $(*=.05, * *=.01, * * *=.001)$. 
Table VII: The Impact of Being Randomly Assigned to 1st Choice School on

Characteristics of School Attending at End of 2002-2003 School Year

\begin{tabular}{|lcc|}
\hline Characteristic of School Attending & Mean & Estimated Impact \\
\hline \hline First choice school & 0.460 & $0.533^{* * *}$ \\
& & $(0.054)$ \\
Not attending CMS in 2002-2003 (Attrition) & 0.098 & -0.018 \\
& & $(0.011)$ \\
School average combined score & -0.073 & $0.129^{* *}$ \\
& & $(0.040)$ \\
Percent free or reduced lunch & 0.463 & $-0.070^{* * *}$ \\
& & $(0.019)$ \\
Percent black or Hispanic & 0.576 & -0.049 \\
& & $(0.026)$ \\
Number of Students & & 2884 \\
\hline
\end{tabular}

Note: Each entry in the table is from a separate regression of the given characteristic of the school a student was attending at the end of the year on whether the student was randomly assigned to her first choice school, controlling for lottery fixed effects, home school fixed effects, and the baseline covariates listed in Table V. Sample includes only students in the randomized priority group with complete baseline data. Standard errors adjust for clustering at the level of the first choice school. Asterisks indicate significance $\left(*=.05,{ }^{* *}=.01\right.$, $* * *=.001)$. 
Table VIII. Instrumental Variables Estimates of the Impact of Attending $1^{\text {st }}$ Choice School on Student Outcomes in 2002-2003

\begin{tabular}{|ccc|}
\hline Student Outcome & Mean & $\begin{array}{c}\text { Average } \\
\text { Treatment Effect }\end{array}$ \\
\hline \hline Non-academic Measures & 0.135 & -0.001 \\
Absent 18 or more days & $(0.023)$ \\
Suspended & 0.201 & 0.012 \\
& & $(0.032)$ \\
Retained & 0.022 & $-0.023^{*}$ \\
& & $(0.009)$ \\
>3 hrs. homework per week & 0.303 & $0.122^{*}$ \\
Academic Performance & & $(0.050)$ \\
Combined test score & -0.005 \\
& -0.086 & $(0.050)$ \\
\hline
\end{tabular}

Note: Each entry in the table is from a separate IV regression of the given student outcome on whether the student was attending her first choice school, using random assignment to the first choice school as an instrument. These regressions control for lottery fixed effects, home school fixed effects, and the baseline covariates listed in table V. Sample includes 2884 students in the randomized priority group with complete baseline data. Sample sizes for homework $(\mathrm{N}=2554)$ and combined test score $(\mathrm{N}=2581)$ are smaller due to missing data on the dependent variable for some students. Standard errors adjust for clustering at the level of the first choice school. Asterisks indicate significance $(*=.05, * *=.01, * * *=.001)$. 
Table IX: Subgroup Estimates of the Effect of Attending a $1^{\text {st }}$-choice School

\begin{tabular}{|c|c|c|c|c|}
\hline Sample & $\begin{array}{l}\text { IV Estimate of } \\
\text { Effect of Attending } \\
1^{\text {st }} \text {-Choice School on } \\
\text { Combined Test } \\
\text { Score }\end{array}$ & Mean $\hat{\beta}_{i}^{A}$ & $\begin{array}{c}\text { Standard } \\
\text { Deviation } \\
\text { of } \hat{\beta}_{i}^{A}\end{array}$ & $\begin{array}{l}\text { Number of } \\
\text { Students }\end{array}$ \\
\hline All Students & $\begin{array}{l}-0.005 \\
(0.050)\end{array}$ & 1.34 & 0.81 & 2581 \\
\hline $\begin{array}{l}\text { Race: } \\
\quad \text { Non-White }\end{array}$ & $\begin{array}{l}-0.067 \\
(0.058)\end{array}$ & 1.12 & 0.71 & 1790 \\
\hline White & $\begin{array}{l}0.172 * \\
(0.073)\end{array}$ & 1.85 & 0.77 & 791 \\
\hline $\begin{array}{l}\text { Income: } \\
\qquad \text { Below Median }\end{array}$ & $\begin{array}{l}-0.100 \\
(0.058)\end{array}$ & 1.01 & 0.61 & 1601 \\
\hline Above Median & $\begin{array}{l}0.130^{*} \\
(0.063)\end{array}$ & 1.90 & 0.78 & 980 \\
\hline $\begin{array}{c}\text { Free Lunch Eligibility } \\
\text { Eligible }\end{array}$ & $\begin{array}{l}-0.061 \\
(0.078)\end{array}$ & 0.74 & 0.44 & 1296 \\
\hline Not Eligible & $\begin{array}{c}0.070 \\
(0.043)\end{array}$ & 1.95 & 0.62 & 1285 \\
\hline $\begin{array}{c}\text { Baseline Test Score } \\
\text { Below Average }\end{array}$ & $\begin{array}{l}-0.040 \\
(0.055)\end{array}$ & 0.83 & 0.52 & 1386 \\
\hline Above Average & $\begin{array}{c}0.066 \\
(0.064)\end{array}$ & 1.94 & 0.65 & 1195 \\
\hline $\begin{array}{c}1^{\text {st }} \text {-Choice School Combined Score } \\
\text { Below Median }\end{array}$ & $\begin{array}{l}-0.036 \\
(0.080)\end{array}$ & 1.07 & 0.69 & 1337 \\
\hline Above Median & $\begin{array}{c}0.047 \\
(0.043)\end{array}$ & 1.64 & 0.82 & 1244 \\
\hline \multicolumn{5}{|c|}{$\begin{array}{l}\text { Note: Each row of column } 2 \text { reports estimates for a different student sub-sample, as indicated. Column } 2 \text { reports IV estimates of } \\
\text { the impact of attending the first choice school on the combined student test score, using random assignment to the first choice } \\
\text { school as an instrument. Regressions control for lottery fixed effects, home school fixed effects, and the baseline covariates } \\
\text { listed in table V. Sample includes only students in the randomized priority group with complete baseline data. Standard errors } \\
\text { adjust for clustering at the level of the first choice school. Asterisks indicate significance }(*=.05, * *=.01 \text {, } * * *=.001 \text { ). Column } 3 \\
\text { reports the average weight that parents place on test scores (Weight) in their school choice decision calculated according to } \\
\text { equation (8). The second column reports the standard deviation of Weight among families in each of the subgroup categories. }\end{array}$} \\
\hline
\end{tabular}


Table X: IV Estimates of the Impact of Attending 1st Choice School with Heterogeneous Treatment by Weight Placed on Academics in Choice Decision

Dependent Variable: Combined Score

\begin{tabular}{l|l} 
(1) & (2) \\
\hline
\end{tabular}

Attended 1st-choice school

$-0.005$

Weight $*$ attended 1st-choice school
P-value for interaction with Weight
Joint p-value on reported coefficients

$-0.105$

Observations

\begin{tabular}{l|l|} 
& $0.077^{*}$ \\
& $(0.031)$ \\
& 0.016 \\
0.924 & 0.031 \\
2581 & 2581 \\
\hline
\end{tabular}

Notes: Each column in the table is from a separate IV regression. The dependent variable is a student's combined standardized test score in the spring of 2003. Each specification reports the coefficients on attending the first choice school and its interaction with the weight that the student places on test scores (Weight) in the school choice decision, using random assignment to the first-choice school and its interaction with Weight as instruments. All specifications control for lottery fixed effects, home school fixed effects, the baseline covariates listed in Table V, and a direct control for the student's Weight estimate. Sample includes only students in the randomized priority group with complete baseline data. Standard errors adjust for clustering at the level of the first choice school. Asterisks indicate significance $(*=.05, * *=.01, * * *=.001)$. 
Table XI: IV Estimates of the Impact of Attending 1st Choice School with Heterogeneous Treatment by Weight Placed on Academics in Choice Decision, Estimated Separately by Student Preference for Racial Mix at School

\begin{tabular}{|c|c|c|c|c|}
\hline $\begin{array}{l}\text { Dependent Variable: } \\
\text { Combined Score }\end{array}$ & \multicolumn{2}{|c|}{$\begin{array}{c}\text { Students Who Prefer } \\
\text { School Less Than } \\
55 \% \text { Black }\end{array}$} & \multicolumn{2}{|c|}{$\begin{array}{c}\text { Students Who Prefer } \\
\text { School at Least } \\
55 \% \text { Black }\end{array}$} \\
\hline Attended 1st-choice school & $\begin{array}{c}0.115 \\
(0.058)\end{array}$ & $\begin{array}{c}0.186 \\
(0.158)\end{array}$ & $\begin{array}{l}-0.054 \\
(0.059)\end{array}$ & $\begin{array}{l}-0.164^{*} \\
(0.078)\end{array}$ \\
\hline Weight $*$ attended 1 st-choice school & & $\begin{array}{l}-0.041 \\
(0.065)\end{array}$ & & $\begin{array}{l}0.098^{*} \\
(0.041)\end{array}$ \\
\hline P-value for interaction with Weight & & 0.533 & & 0.019 \\
\hline Joint $p$-value on reported coefficients & 0.052 & 0.097 & 0.250 & 0.053 \\
\hline Observations & 870 & 870 & 1711 & 1711 \\
\hline
\end{tabular}

Notes: Each column in the table is from a separate IV regression. The dependent variable is a student's combined standardized test score in the spring of 2003. Each specification reports the coefficients on attending the first choice school and it interaction with the weight that the student places on test scores (Weight) in the school choice decision, using random assignment to the first-choice school and its interaction with Weight as instruments. All specifications control for lottery fixed effects, home school fixed effects, the baseline covariates listed in Table V, and a direct control for the student's Weight estimate. Sample includes only students in the randomized priority group with complete baseline data. Student preference for racial composition in the school is each student's posterior estimate of the value that maximizes their quadratic utility in \%black at the school. Standard errors adjust for clustering at the level of the first choice school. Asterisks indicate significance $(*=.05, * *=.01, * * *=.001)$. 
Table XII. IV Estimates of the Impact of Attending 1st Choice School with Heterogeneous Treatment Effect Associated With Characteristics of the School Chosen.

\begin{tabular}{|c|c|c|c|c|c|c|c|c|c|}
\hline \multirow[b]{2}{*}{ Attended 1st-choice school } & \multirow{2}{*}{$\begin{array}{c}\begin{array}{c}\text { Base } \\
\text { Model }\end{array} \\
\\
-0.105 \\
(0.074)\end{array}$} & \multicolumn{2}{|c|}{$\begin{array}{c}\text { Interaction With } \\
\text { Difference in } \\
\text { Average School } \\
\text { Sores } \\
\end{array}$} & \multicolumn{2}{|c|}{$\begin{array}{l}\text { Interaction with } \\
\text { Average Score in } \\
\mathbf{1}^{\text {st }} \text {-Choice School }\end{array}$} & \multicolumn{2}{|c|}{$\begin{array}{l}\text { Interaction With } \\
\text { Average Weight } \\
\text { of Students in } 1^{\text {st }} \text { - } \\
\text { Choice Lottery } \\
\end{array}$} & \multicolumn{2}{|c|}{$\begin{array}{c}\text { Interaction With } \\
1^{\text {st }} \text {-Choice School } \\
\text { Fixed-Effects }\end{array}$} \\
\hline & & $\begin{array}{c}0.000 \\
(0.057)\end{array}$ & $\begin{array}{l}-0.100 \\
(0.077)\end{array}$ & $\begin{array}{l}-0.015 \\
(0.049)\end{array}$ & $\begin{array}{l}-0.089 \\
(0.073)\end{array}$ & $\begin{array}{c}-0.164 \\
(0.132)\end{array}$ & $\begin{array}{c}-0.166 \\
(0.132)\end{array}$ & n.a. & n.a. \\
\hline \multicolumn{10}{|l|}{ Attended 1st-choice school * } \\
\hline Weight & $\begin{array}{l}0.077 * \\
(0.031)\end{array}$ & & $\begin{array}{l}0.077^{*} \\
(0.032)\end{array}$ & & $\begin{array}{c}0.061 \\
(0.041)\end{array}$ & & $\begin{array}{c}0.043 \\
(0.053)\end{array}$ & & $\begin{array}{c}0.074 \\
(0.071)\end{array}$ \\
\hline Difference in average school scores & & $\begin{array}{c}-0.017 \\
(0.072)\end{array}$ & $\begin{array}{l}-0.019 \\
(0.077)\end{array}$ & & & & & & \\
\hline Average score in $1^{\text {st }}$-choice school & & & & $\begin{array}{c}0.136 \\
(0.090)\end{array}$ & $\begin{array}{c}0.082 \\
(0.114)\end{array}$ & & & & \\
\hline Average Weight of students in lottery & & & & & & $\begin{array}{c}0.121 \\
(0.075)\end{array}$ & $\begin{array}{c}0.081 \\
(0.112)\end{array}$ & & \\
\hline P-value for interaction with Weight & 0.016 & & 0.018 & & 0.149 & & 0.427 & & 0.293 \\
\hline P-value for other interaction(s) & & 0.813 & 0.803 & 0.136 & 0.474 & 0.109 & 0.472 & 0.066 & 0.203 \\
\hline Joint $p$-value on reported coefficients & 0.031 & 0.963 & 0.071 & 0.241 & 0.02 & 0.13 & 0.039 & 0.069 & 0.177 \\
\hline Observations & 2581 & 2581 & 2581 & 2581 & 2581 & 2581 & 2581 & 2475 & 2475 \\
\hline
\end{tabular}

